\title{
HERMENÊUTICA JURÍDICA TRIBUTÁRIA: REDUÇÃO DOS EFEITOS DA COMPLEXIDADE DAS NORMAS TRIBUTÁRIAS
}

\author{
Silzia Alves Carvalho ${ }^{1}$ \\ Gabriela Machado Rennó ${ }^{2}$
}

\section{RESUMO:}

Cinge-se o artigo em abordar aspectos da hermenêutica jurídica tributária, relacionando os métodos hermenêuticos aos casos concretos, uma vez que a complexidade das normas tributárias aliada à ausência de clareza nos métodos interpretativos utilizados ocasiona multiplicidade de litígios e sobrecarga judicial. Nessa linha, além da análise dogmática da matéria, o artigo fará estudo de caso a partir do RE 574.706 PR, julgamento que perdurou por anos, devido às divergências interpretativas de normas tributárias. Por fim, pretende-se abordar conclusões quanto a utilização de métodos hermenêuticos transparentes e solidificados, especialmente no RE 574.706 PR, em prol da segurança jurídica em matéria tributária.

PALAVRAS-CHAVE: Hermenêutica. Tributário. Litigiosidade. Segurança Jurídica. Transparência.

\section{TAX LEGAL HERMENEUTICS: REDUCING THE EFFECTS OF COMPLEXITY IN TAX RULES}

\begin{abstract}
:
The article girds itself on addressing hermeneutic legal tax aspects, relating hermeneutic methods to specific cases, since the complications of tax rules combined with the lack of clarity in interpretative methods cause a multiplicity of litigation and judicial inspection. Along these lines, in addition to the dogmatic analysis of the matter, the article makes a case study based on RE 574.706 PR, a judgment that it lost for years, due to interpretative differences in tax rules. Finally, plan to address the use of transparent and solid hermeneutic methods, especially in RE 574.706 PR, for the sake of legal certainty in tax matters.
\end{abstract}

KEYWORDS: Hermeneutics. Tax. Litigation. Legal Security. Transparency.

\section{INTRODUÇÃO}

A priori, o tema a ser abordado no presente artigo origina-se tanto da práxis quanto da teoria, posto que tem como objeto a investigação teórica e empírica da intepretação na

\footnotetext{
${ }^{1}$ Doutora e Mestra em Direito pela Pontifícia Universidade Católica de São Paulo. Professora permanente do Programa de Pós-Graduação em Direito e Políticas Públicas da Universidade Federal de Goiás. E-mail: silzia.ac@gmail.com

${ }^{2}$ Mestranda em Direito e Políticas Públicas no Programa de Pós-Graduação em Direito e Políticas Públicas da Universidade Federal de Goiás. Graduada em Direito pela Universidade Federal de Goiás. Advogada. E-mail: gabriela.renno@hotmail.com
} 
aplicação das normas em Direito Tributário, visando, dessa forma, contribuir com propostas relacionadas à utilização de métodos hermenêuticos tributários no atual contenciosos judicial tributário.

O debate em questão se insere na atualidade na medida em que a hermenêutica tributária está em constante desenvolvimento, dado que proliferam conflitos de ordem interpretativa entre os julgadores, o fisco e os contribuintes, ocasionando multiplicidade de demandas e abarrotamento dos Tribunais.

Insta suscitar, nesse contexto, que grande parte do litígio tributário brasileiro envolve aspectos puramente interpretativos, considerando que conceitos constitucionais e legais são utilizados livremente e de acordo com os interesses particulares do intérprete, ocasionando, assim, a sobrecarga judicial.

$\mathrm{Na}$ mesma linha, tem-se que a complexidade das normas tributárias clama por interpretação tributária transparente e clara, por meio de utilização de métodos integrados que assegurem a confiança legítima, as limitações institucionais e a ponderação como limitação ao subjetivismo judicial.

Com efeito, apreende-se que o sentido é resultado da interpretação, a qual depende do argumento no qual se baseia a técnica e da primazia entre os argumentos. Pressupõe-se a existência de um sentido a ser desvendado por meio de procedimento controlável, ou seja, captar o sentido da norma exige esforço interpretativo com base em clara e sólida metodologia para que se alcance o sentido da norma ao caso concreto.

Nota-se, por fim, que o imbróglio atual enfrentado pelo Sistema Tributário Nacional é a prática argumentativa utilizada para produzir determinado sentido. Até obter-se um resultado, há um caminho de interpretação, o qual precisa ser transparente e objetivo, por meio da objetividade semântica, métodos solidificados e da independência do sujeito quanto aos critérios de julgamento do objeto. Além disso, deve-se zelar pela segurança jurídica no procedimento discursivo para chegar-se ao conteúdo pretendido pela norma.

Diante de tal cenário, emerge a relevância de se conjecturar esforços, por meio de estudos jurídicos relacionados à hermenêutica tributária, em vistas a consolidar a hermenêutica no direito tributário como instrumento transparente e apto a alcançar o intuito e sentido normativo, o qual não é propriedade do objeto, mas procedimento de construção do objeto. 


\section{HERMENÊUTICA JURÍDICA TRIBUTÁRIA}

O reconhecimento da mens legis, por meio da interpretação da lei, é a forma de operacionalizar a norma jurídica. Faz-se imprescindível analisar a interpretação das normas jurídicas em direito tributário para que haja uma coerência e unidade no sistema normativo tributário, de forma, ainda, que não existam prejuízos para o Fisco ou para o contribuinte.

A priori, é de se destacar que a interpretação é fundamental para a aplicação do Direito, dado que para se declarar o que está determinado em uma lei é necessário realizar uma atividade lógica de análise do mandamento legal em toda a sua plenitude e extensão.

Do mesmo modo, a hermenêutica jurídica é uma ciência que se propõe a estudar técnicas possíveis de interpretação, de modo a estabelecer os critérios considerados razoáveis de interpretação de uma norma. Nota-se, pois, que a interpretação da lei é um dos objetivos da hermenêutica jurídica, a qual estuda sistematicamente os processos de interpretação, integração e aplicação do Direito.

O professor Tércio Sampaio Ferraz Júnior trata a hermenêutica como a forma de racionalizar a norma, isto é, a racionalidade do jurista que faz a lei falar. Além disso, aponta que a hermenêutica, ao realizar a tarefa interpretativa do uso competente de uma língua, pode ser caracterizada como discurso de poder e de violência simbólica (FERRAZ JÚNIOR, 2013).

Não obstante, insta observar que o ato de interpretar é o mesmo independentemente do ramo do Direito. Deve-se, pois, buscar o sentido da norma que alcance a justiça material em um cenário integrado de ramos do direito.

Em direito tributário, há algumas regras específicas de interpretação da legislação tributária estabelecidas no Código Tributário Nacional. Destaca-se também que a integração da legislação tributária deve ser abarcada levando em conta um sistema interpretativo integrado que principalmente observe os ditames constitucionais.

Nesse viés, a ciência da interpretação se divide em diversos métodos de interpretação, e, basicamente, consiste em um árduo trabalho de investigação, cujo objetivo é compreender o sentido e significado da lei. Em outras palavras, ao buscar decifrar o que pensou o legislador para elaborar a lei, visa-se delimitar o alcance do raciocínio posto pelo legislador na norma.

Outrossim, cumpre destacar que o processo hermenêutico de interpretação das leis, na visão do doutrinador Aliomar Baleeiro, é a "a arte de extrair do texto abstrato, geral e 
necessariamente conciso, tudo quanto nele se contém, para os fins visados pelo legislador" (BALEEIRO, 1974).

Com efeito, para interpretar uma lei é preciso captar adequadamente o seu significado e alcance. Em matéria tributária, além do preceituado no CTN, o intérprete pode socorrer-se de métodos de interpretação derivados da hermenêutica, valendo-se de processos clarificadores dos institutos jurídicos.

A esse propósito, Hugo de Brito Machado ressalta que "O intérprete não cria, não inova, limitando-se a considerar o mandamento legal em toda a sua plenitude, declarando-lhe o significado e o alcance" (MACHADO, 2013).

Ademais, observa-se que nas relações jurídicas tributárias, diversos conflitos interpretativos são vislumbrados devido a interpretações realizadas a partir de posições antagônicas, quais sejam: contribuinte e fisco. Isso, pois, a mesma norma legal pode ser enxergada sob diferentes óticas de acordo com os interesses em disputa.

Levando isso em conta, a hermenêutica jurídica deve ser alvo de um sistema interpretativo integrado, que forneça o alcance da norma, em seus sentidos literal, histórico, teleológico e sistemático.

Assim, a hermenêutica jurídica a ser aplicada ao direito tributário deve limitar a extensão dos conceitos jurídicos e demarcar as hipóteses que se estende a sua aplicação, de forma que o Direito atue conjuntamente com Estado para assegurar a realização da justiça em sentido de liberdade e igualdade entre os sujeitos de direito.

\subsection{REGRAS E MÉTODOS DE INTERPRETAÇÃO DA LEGISLAÇÃO TRIBUTÁRIA}

No que tange as regras de interpretação da legislação tributária, verifica-se que estas não são pré-fixadas, no entanto, o Código Tributário Nacional (CTN) traz algumas orientações a serem observadas ao se interpretar a legislação tributária, dado que conforme explanado no tópico supra, é crucial captar o alcance da lei para aplicá-la devidamente.

Veja-se, pois, que o CTN dispões sobre o estudo da interpretação da legislação tributária no Capítulo IV do Título 1, artigos 107 a 112. Inicialmente, o artigo 107 já estabelece que a interpretação da legislação tributária deve ser realizada conforme as diretrizes do próprio Código Tributário Nacional, ou seja, por mais que seja necessário 
recorrer a instrumentos jurídicos de interpretação, não se pode haver interpretação que colida com o assentado no CTN.

$\mathrm{O}$ artigo 111 do $\mathrm{CTN}$, por sua vez, indica que a legislação deve ser interpretada literalmente quando se tratar de suspensão ou exclusão do crédito tributário, outorga da isenção ou dispensa do cumprimento de obrigações acessórias.

Nesse sentido, Paulo de Barros valoriza a análise do discurso como modelo de interpretação tributária, assevera que a partir da interpretação literal o intérprete estaria impedido de aprofundar-se nos planos semânticos e pragmáticos por preponderar a investigação sintática, o que pode corresponder a uma formulação semântica inválida (CARVALHO, 2017).

O supracitado doutrinador, critica o método literal, sob o seguinte enfoque: "Prisioneiro do significado básico dos signos jurídicos, o intérprete da formulação literal dificilmente alcançará plenitude do comando legislado, exatamente porque se vê tolhido de buscar a significação contextual e não há texto sem contexto. "(CARVALHO, 2017).

Não obstante, corrobora com tal entendimento o doutrinador Hugo de Brito ao concluir que utilizar o método literal, ou método gramatical, isoladamente, é insuficiente para esclarecer com segurança o alcance da regra jurídica. Apesar de indispensável, se usado sem os outros elementos de interpretação, o método literal pode levar a erros (MACHADO, 2013).

O método histórico, advindo da hermenêutica, visa investigar o direito anterior ao vigente, de modo a comparar a norma atual com a que lhe antecedeu, examinando também o anteprojeto de lei, as emendas sofridas pela lei, a vontade do legislador, circunstâncias históricas, os debates parlamentares e também todo o processo legislativo.

Observa-se, nesse viés, que utilizar o método histórico envolve trazer elementos externos ao direito para interpretá-lo, os quais embora não estejam inseridos no ordenamento jurídico, possuem relevante papel a interpretação legal, tais como as tendências circunstanciais que cercaram a produção da norma.

Em relação ao método teleológico, este tende a acentuar a finalidade da norma, em outras palavras, indicar a direção finalística do comando legislado (CARVALHO, 2017). Busca-se, por meio da metodologia teleológica, o sentido de uma regra de acordo com o fim para o qual ela foi elaborada, tendo em vista que o intérprete não pode extrair de uma norma significação contrária à finalidade visada pelo legislador. 
Ocorre que, a atividade de compreensão da mens legis é complexa, pois, pode-se questionar as finalidades de certos comandos legislativos, os quais, por vezes, possuem condão político-ideológico. Todavia, deve-se ter em mente que a mens legis e a mens jus precisam estar em consonância, sem que haja a prevalência de destinação de uma sobre a outra.

Não obstante, é necessário suscitar que existem também normas em direito tributário que induzem comportamentos, estimulam ou desestimulam condutas dos contribuintes. E, ao interpretar utilizando o método teleológico pode-se dar margem para uma interpretação econômica da norma fiscal, a qual considera, em síntese, e natureza econômica da norma e a finalidade arrecadatória como premissa para a interpretação teleológica, a qual, como é sabido, não é o único objetivo da norma tributária.

Já no método sistemático, o intérprete verifica o sentido da lei através de uma integração normativa com todo o regramento jurídico. De forma sistemática, primeiro verifica-se a posição de uma regra dentro do próprio dispositivo legal que ela se encontra, depois se analisa a mesma regra dentro das demais regras contidas no mesmo ramo do Direito, e, por fim, se analisa a regra com integrante de todo o sistema jurídico.

Tal método visa contemplar a interpretação integrada do ordenamento jurídico, para que assim não haja interpretações normativas isoladas, posto que o Direito é um emaranhado de normas que se interligam.

Em direito tributário, por exemplo, é notoriamente visível que as normas tributárias possuem correlação direta com as normas constitucionais, e, por isso não podem ser interpretadas isoladamente. Fato este que nos faz ponderar, além da integralidade de normas em um sistema jurídico, a sequência de níveis hierárquicos no momento de aplicar uma norma no sistema.

Evidencia-se, assim, que o significado da norma depende do contexto em que ela se insere. Para grande parte da doutrina este é o método mais apropriado para definir definitivamente o sentido de uma norma jurídica. Nesse esteio, inclusive, o professor Paulo de Barros assevera que é o método por excelência capaz de prevalecer, dado que pressupõe o emprego dos demais métodos ao ditar que o intérprete deve observar a regra em cotejo com a multiplicidade dos comandos normativos (CARVALHO, 2017).

É relevante observar que por mais que o CTN estabeleça comandos normativos de ordem interpretativa, a doutrina direciona o entendimento da questão para uma aplicação 
integrada dos métodos de interpretação, na busca da razão de ser de uma lei. Isto é, a interpretação não está sujeita a uma técnica ou regra específica, mas sim a um conjunto de métodos e formas que devem ser observados de maneira integrativa com o ordenamento jurídico.

Nessa perspectiva, a priori, pode-se concluir que o CTN estabelece regras específicas aplicáveis ao direito tributário, e, possibilita também a utilização de métodos interpretativos advindos da ciência da hermenêutica (interpretação literal; lógico sistémica; teleológica; histórica), os quais deverão ser utilizados de forma conjunta e integrada.

\section{MÉTODOS INTERPRETATIVOS E INTERPRETAÇÃO CONFORME A CONSTITUIÇÃO FEDERAL}

Desde longa data discute-se, em sede doutrinária e jurisprudencial, acerca das divergências interpretativas que acabam por confundir os aplicadores do Direito e incrementar o contencioso fiscal do país, vide o caso do conceito de "faturamento" e "receita bruta", discutido por anos no Judiciário e que será a posteriori analisado.

Destarte, vislumbra-se que o sentido da norma se encontra condicionado à prática argumentativa, isto é, a força normativa depende do acordo feito no processo de interpretação. Tal fato evidencia a necessidade de uma hermenêutica capaz de trazer segurança jurídica e eficácia ao sistema tributário, o que poderá resultar na redução da litigiosidade fiscal.

Diante das circunstâncias do desenvolvimento da interpretação jurídica nas últimas décadas e ante a ineficácia e anacronismos das normas tributárias que dispõem sobre interpretação, faz-se crucial desmotivar a cultura do litígio tributário por meio da utilização eficiente de métodos e critérios hermenêuticos claros na aplicação norma tributária, capazes de induzir à redução dos efeitos da complexidade na interpretação e aplicação da legislação tributária.

Entende-se, nesse viés, que uma das formas de simplificar o atual sistema tributário nacional é a utilização critérios e métodos hermenêuticos transparentes de aplicação do Direito Tributário, de modo que haja convergência entre os princípios da segurança jurídica, da isonomia, da imparcialidade e da justiça fiscal. Dessa forma, espera-se que a simplicidade do sistema acarrete maior eficiência na arrecadação de tributos, pois desestimulará a evasão de receitas fiscais. 
Em outras palavras, a redução da complexidade na interpretação e aplicabilidade da legislação tributária, por meio de critérios estruturais e metodológicos pré-definidos, deverá implicar numa maior eficiência na entrada de recursos privados junto aos cofres públicos.

Ademais, destaca-se que a Constituição Federal é relevante para a concretização das normas tributárias, uma vez que é um dispositivo normativo único e analítico. Nesse esteio, além de abarcar princípios jurídicos que informam a correta aplicação da legislação tributária, há várias regras jurídicas determinantes na Constituição, tais como a irretroatividade, anterioridade, capacidade contributiva, as imunidades, dispositivos de competência tributária, e, sobretudo, a constitucionalização de conceitos de Direito Privado e Público na previsão de competências tributárias (ANDRADE, 2010).

Nota-se que os preceitos constitucionais acabam por tracejar as características e finalidades da legislação desenvolvida a posteriori. Pode-se analisar, dessa forma, que o sistema tributário consiste em um subsistema constitucional, formado por normas que versam da matéria tributária em nível constitucional, conforme já salientado.

Paulo de Barros assevera que a Constituição, por ser um instrumento semirrígido, o que acarreta pouca mobilidade à atividade legislativa infraconstitucional, e, por conseguinte, observamos um sistema tributário de acentuada rigidez. Além disso, exemplifica que a profusão de comandos relativos à tributação foi registrada por Aliomar Baleeiro, o qual separou mais de cem regras tributárias insertas no texto da Carta Magna. (CARVALHO, 2017).

Além da necessária clareza nos métodos interpretativos utilizados para interpretar-se o Direito Tributário pelos julgadores, portanto, os operadores do Direito precisam partir de uma compreensão constitucional do direito tributário, a qual não pode ter um papel isolado no sistema, mas sim integrado.

\section{ANÁliSE DE CASO CONCRETO: MÉTODOS HERMENÊUTICOS UTILIZADOS NO RE 574.706 PARANÁ}

Após explanar aspectos gerais da interpretação tributária, o presente artigo buscar-seá, por fim, demonstrar os métodos interpretativos utilizados pelo Fisco e pelo Supremo no RE 574.706 PR como forma de ilustrar a relevância da utilização de métodos hermenêuticos 
claros e solidificados na aplicação consistente e justa das normas jurídicas em casos concretos.

O julgamento do RE 574.706 PR colocou fim a um debate que perdurou anos entre contribuintes e Fisco, os quais utilizaram distintos meios interpretativos para analisar a tese em questão, sendo consolidado pelo Supremo o entendimento, tanto buscado pelas empresas, de que o ICMS não é abarcado pelo conceito de faturamento, e, por isso, não integra as bases de cálculo do PIS e da COFINS.

Isso, pois, os contribuintes buscaram demonstrar que apesar do ICMS constar do valor final de venda de uma mercadoria, o ICMS não é faturamento, dado que tal parcela é ônus fiscal de arrecadação. O STF abarcou tal raciocínio ao indicar que faturamento se restringe ao valor recebido pelo contribuinte no exercício de sua atividade econômica resultante no valor total de suas operações típicas.

Veja-se, nesse sentido, que por outro lado, a Procuradoria Geral da Fazenda Nacional intentou prevalecer o entendimento ampliativo do conceito de receita bruta, de modo que o conceito comporte a inclusão dos valores pertinentes ao ICMS, pois para a Fazenda, a receita bruta abrange a soma de todas as receitas decorrentes das atividades operacionais típicas com todas as demais receitas auferidas pela pessoa jurídica, sem restrições.

Não obstante, além de ampliar o conceito de receita bruta, a Fazenda tentou conduzir ao raciocínio de que os valores referentes ao ICMS são sujeitos ao PIS e a COFINS porque se trata de parcelas, como outras quaisquer, que compõem o custo do bem ou serviço, balizando a formação do preço e repercutindo nas receitas auferidas pela empresa, assim como preceituado na $\mathrm{ADC} \mathrm{n}^{\circ} 18$ em relação à incidência de Contribuição para o PIS/PASEP e COFINS sobre o ICMS.

À primeira vista pode-se dizer que a Procuradoria utilizou os métodos hermenêuticos ampliativo e histórico para abarcar uma conceituação de faturamento além da expressão literal da norma, e, não obstante, utilizou o método teleológico no sentido de tentar conduzir a finalidade da norma à arrecadação fiscal, tentando assegurar a máxima eficácia tributária e os melhores resultados fiscais ao erário.

A interpretação do STF, contudo, utilizando o princípio da proporcionalidade na aplicação da norma tributária, prevaleceu, uma vez que o Supremo interpretou favoravelmente ao contribuinte, de forma a não alargar conceitos, utilizando, ainda, uma completude de métodos hermenêuticos, quais sejam: histórico, teleológico, literal e sistemático. 
Em outras palavras, o STF atentou-se ao método literal ao se ater ao significado exarado na legislação de "faturamento"; ao método histórico ao levar em conta toda a evolução legislativa sobre o conceito; ao método teleológico ao ponderar a finalidade da norma, levando em conta a justa finalidade do comando legislativo; e ao sistemático ao interpretar o conceito constitucional de faturamento considerando a integridade do ordenamento jurídico, principalmente no que tange as normas tributárias constitucionais.

Outrossim, apesar de criticado pela doutrina, o método restritivo foi crucial no deslinde da lide em análise, visto que foi utilizado para evitar a tentativa de alargamento indevido do conceito constitucional de faturamento. Ou seja, através de uma interpretação à luz da constituição e de um conjunto de métodos interpretativos, principalmente o método restritivo ao conceito de faturamento, entende-se que houve análise adequada e proporcional da problemática.

Insta destacar, ainda, que o êxito na utilização do método interpretativo restritivo, ou literal como muitos o denominam, se deu por este não ter sido utilizado isoladamente, mas sim com a completude de meios hermenêuticos, que levaram a uma interpretação condizente com a Constituição e com o princípio da proporcionalidade na aplicação da norma tributária.

A interpretação que prevaleceu no referido caso foi além dos interesses do Fisco ou dos contribuintes, dado que visou equilibrar a temática com razoabilidade para aferir o conceito de faturamento, de forma a não desvirtuar a finalidade da norma constitucional, sem tender a interpretações casuísticas ou econômicas, ou seja, utilizou-se devidamente os métodos: restritivo, histórico e teleológico.

O STF dedicou muitas sessões de julgamento para elucidar a definição de faturamento, em razão da complexidade do tema. O histórico legislativo e jurisprudencial do tema foi utilizado para isso, relevando a utilização do método hermenêutico histórico para poder se chegar a finalidade da norma, e como dito, utilizando, conjuntamente, o método hermenêutico teleológico para vislumbrar a intenção do legislador.

É válido observar que o método sistemático também foi contemplado no julgamento, dado que se nota verdadeiro comprometimento dos Ministros em interpretar a norma constitucional em conformidade com todo o ordenamento jurídico, considerando, principalmente, o direito tributário e o direito empresarial.

Assim, o método hermenêutico decisivo para a lide foi o método restritivo, visto que foi o método utilizado pela interpretação vencedora, a qual utilizou a literalidade da norma 
constitucional, de modo a evitar ampliações ao conceito de faturamento e, assim, evitar cobranças inconstitucionais aos contribuintes.

Prevaleceu, assim, a valorização da fidelidade à literalidade do texto constitucional, evidenciando que o ICMS não é incluído pelo contribuinte como receita ou faturamento, dado que ele haverá de repassar os valores à Fazenda Pública.

Não obstante, por fim, o exemplo em análise demonstra que, mesmo após mais de vinte anos de lide judicial, a problemática interpretativa inerente ao caso não foi claramente demonstrada pelos Julgadores, dado que estes utilizaram métodos hermenêuticos intuitivamente, sem os especificar e pormenorizar para a adequada compreensão dos contribuintes à luz do princípio da segurança jurídica.

\section{CONSIDERAÇÕES FINAIS}

Diante do exposto no presente artigo, diversas conclusões hermenêuticas podem ser obtidas após da análise do caso concreto suscitado acima, dado que as distintas visões do fisco e do STF, inclusive entre os Ministros do Supremo, nos permitem analisar os métodos e meios de interpretação utilizados para solucionar a problemática e extrair a finalidade da norma. Além disso, nos permitem aferir que, de fato, não há transparência e clareza na utilização de métodos hermenêuticos em direito tributário, visto que não há como aferir de plano qual a interpretação deve prevalecer em matéria tributária.

Os Ministros que proferiram os votos vencedores no RE 574.706 PR não se deixaram valer de argumentações econômicas e ampliativas, das quais não condizem com o intuito de proteção da Constituição, cabível ao STF. No entanto, a lide tributária perdurou por mais de vinte anos, o que, inevitavelmente, instaurou um cenário de insegurança jurídica aos operadores do direito, os quais não possuíam certeza acerca dos métodos hermenêuticos adequados para a solução da controvérsia.

Insta observar, contudo, que prevaleceu no STF a utilização adequada dos métodos de interpretação da lei tributária e da Constituição Federal, os quais se mostraram proporcionais na definição do alcance e limites do termo "faturamento" exarado no texto constitucional.

Por outro lado, a interpretação da Procuradoria Geral da Fazenda Nacional demonstrou desvios da intenção legislativa da norma ao intentar ampliar a arrecadação de 
forma indevida. Trata-se da famigerada hermenêutica dos interesses, a qual deve ser prontamente coibida pelos julgadores.

$\mathrm{O}$ intuito arrecadatório da Fazenda, dessa forma, acaba por justificar as inúmeras tentativas de prevalecimento da interpretação ampliativa, teleológica desvirtuada e legislativa histórica sem abranger uma interpretação à luz, primordialmente, da Constituição Federal.

Nesse viés, insta observar que cabe aos contribuintes confiar no papel desempenhado pelos Julgadores em matéria tributária de observância obrigatória ao princípio da segurança jurídica, para, dessa forma, evitar um cenário de prevalência da hermenêutica dos interesses, dado que os julgadores devem valer-se de hermenêutica clara e consistente ante ao caso concreto.

Destarte, cumpre destacar que a completude de utilização dos métodos hermenêuticos sistematicamente é essencial para evitar equívocos na apreciação dos casos concretos, visto que utilizando apenas um método interpretativo como foco, seja o literal, o ampliativo, o histórico, o econômico ou o teleológico, há consideráveis riscos de se incorrer em uma solução ineficaz para a lide, visto que a limitação da interpretação jurídica aos interesses e preocupações de determinada parte não conseguirão alcançar a justiça material e formal tão zelada pelo direito e, almejada na atuação do Supremo Tribunal Federal.

Conclui-se que ao contribuinte resta confiar que o Supremo Tribunal Federal, como guardião da Constituição, coíba a prevalência de um ambiente marcado por violações aos comandos legislativos exarados da Constituição Federal, através de interpretações desvirtuadas do intuito do legislador.

Ante ao exposto, conclui-se, ainda, que a hermenêutica em matéria tributária necessita ser repensada, uma vez que, no cenário atual, as interpretações são controvertidas e pouco fundamentadas, fato que gera, inevitavelmente, insegurança aos contribuintes.

Ademais, tem-se que com interpretações obscuras há notório fomento à cultura do litígio tributário, realidade em que os contribuintes não confiam no Direito e não compreendem como as normas devem ser interpretadas.

Por isso, a atuação dos operadores do direito com base em robusta e transparente hermenêutica é essencial para a simplificação do Sistema Tributário Nacional e deve ser incentivada, em prol da observância ao princípio da segurança jurídica em matéria tributária e da necessária redução da complexidade das normas tributárias. 


\section{REFERÊNCIAS BIBLIOGRÁFICAS}

ADEODATO, Joao Maurício. Uma teoria retórica da norma jurídica e do direito subjetivo. $2^{\mathrm{a}}$ ed. São Paulo: Noeses, 2014.

ANDRADE, José Maria Arruda de. Interpretação da Norma Tributária. 1. ed. São Paulo: MP Editora, 2006.

ANDRADE, José Maria Arruda de. Interpretação e aplicação da lei tributária: da consideração econômica da norma tributária à análise econômica do direito. In. MACHADO, Hugo de Brito. (Coord.) Interpretação e aplicação da lei tributária. São Paulo: Dialética / ICET, 2010.

ATALIBA, Geraldo. Sistema constitucional tributário brasileiro. São Paulo: Revista dos Tribunais, 1968.

ÁVILA, Humberto. Competências tributárias: um ensaio sobre a sua compatibilidade com as noções de tipo e conceito. São Paulo: Malheiros, 2018. (72 p.)

ÁVILA, Humberto. Comportamento anticoncorrencial e direito tributário. In. FERRAZ, Roberto (coord.). Princípios e limites da tributação 2: os princípios da ordem econômica e a tributação. São Paulo: Quartier Latin, 2009.

ÁVILA, Humberto. Teoria da Igualdade Tributária. $3^{\text {a }}$ edição. São Paulo: Malheiros, 2015, p. 39-150.

ÁVILA, Humberto. Teoria da Segurança Jurídica. $4^{\mathrm{a}}$ edição. São Paulo: Malheiros, 2016, p. 113-647.

ÁVILA, Humberto. Teoria dos Princípios. $18^{\text {a }}$ edição. São Paulo: Malheiros, 2018, p. 149161.

BALLEIRO, Aliomar. Direito Tributário Brasileiro 6 ${ }^{\mathrm{a}}$.ed. Rio de Janeiro: Forense, 1974.

BARRETO, Paulo Ayres. Ordenamento e sistema jurídicos. In. CARVALHO, Paulo de Barros (Coord.); CARVALHO, Aurora Tomazini de (org.). Constructivismo lógicosemântico. Vol. I. São Paulo: Noeses, 2014.

BARROSO, Luís Roberto. Interpretação e aplicação da Constituição: fundamentos de uma dogmática constitucional transformadora. 7. ed. São Paulo: Saraiva, 2009. 
BERCOVICI, Gilberto. Política Econômica e Direito Econômico. In: Revista Fórum de Direito Financeiro e Econômico. Ano 1, v. 1. Belo Horizonte: Fórum, março/agosto, 2012. BOBBIO, Norberto. Teoria da Norma Jurídica. 5 ed. São Paulo, Edipro, 2014.

BOBBIO, Norberto. Teoria da Ordenamento Jurídico. 6 ed. Brasília: Editora Universidade de Brasília, 1995.

BONAVIDES, Paulo. Curso de Direito Constitucional. 10ª ed. São Paulo: Malheiros, 2000.

BORGES, José Souto Maior. Um Ensaio Interdisciplinar em Direito Tributário: Superação da Dogmática. Revista Dialética de Direito Tributário, nº 211, 2013.

BRASIL, Lei n ${ }^{\circ}$ 5.172, de 25 de outubro de 1966. Institui o Código Tributário Nacional. Diário Oficial da República Federativa do Brasil, Brasília, 27 out. 1966. Disponível em: http://www.planalto.gov.br/ccivil_03/LEIS/L5172.htm. Acesso em 30 jul. 2019.

BRASIL. Supremo Tribunal Federal. Recurso Extraordinário: 574.706 Paraná- PR. Relatora: Ministra Cármen Lúcia. mar. 2017.

BRASIL. Supremo Tribunal Federal. Recurso Extraordinário: RE 240.785 Minas Gerais MG. Relator: Ministro Ricardo Lewandowski. out. 2014.

BRASIL. Constituição (1988). Constituição da República Federativa do Brasil. Brasília, DF: Senado Federal: Centro Gráfico, 1988.

CAMARGO, Ricardo Antônio Lucas. O Mercado Interno, o Patrimônio Público e o Artigo 219 da Constituição Brasileira de 1988 - Bases para sua Interpretação. In: Direito Econômico e Direito Administrativo: O Estado e o Poder Econômico. Porto Alegre: Sergio Antonio Fabris Editor, 2006, pp. 85-97.

CAMPILONGO, Celso Fernandes. O direito na sociedade complexa. $2^{\mathrm{a}}$ ed. São Paulo: Saraiva, 2011.

CARRAZZA, Roque Antonio; Curso de Direito Constitucional Tributário, 17 ed., São Paulo: Malheiros, 2002.

CARVALHO, Cristiano. Teoria da Decisão Tributária. São Paulo: Saraiva, 2013.

CARVALHO, Paulo de Barros. Curso de Direito Tributário. 28. ed. São Paulo: Saraiva, 2017. 
COÊLHO, Sacha Calmon Navarro. Curso de Direito Tributário Brasileiro. 15. ed. São Paulo: Editora Forense, 2016.

CONRADO, Paulo Cesar. Perspectivas do contencioso tributário com o novo Código de Processo Civil. In: Paulo de Barros Carvalho; Priscila de Souza. (Org.). Direito tributário e os novos horizontes do processo. 1 ed. São Paulo: Noeses, 2015, v. 1.

DA SILVA, José Afonso. Curso de Direito Constitucional Positivo. 26. ed. São Paulo: Malheiros Editores Ltda., 2006.

DERZI, Misabel Abreu Machado. Modificações da jurisprudência no Direito Tributário: Proteção da confiança, boa-fé objetiva e irretroatividade como limitações constitucionais ao poder de tributar. São Paulo: Noeses, 2009.

FERRAZ JUNIOR, Tércio Sampaio. Introdução ao Estudo do Direito: técnica, decisão, dominação. 7. ed. São Paulo: Atlas, 2013.

FERRAZ JUNIOR, Tercio Sampaio. O Direito, entre o Passado e o Futuro. São Paulo: Noeses, 2014.

FERRAZ, Roberto Catalano Botelho. et. al. Princípios e Limites da Tributação. São Paulo: Quartier Latin, 2005.

FERRAZ, Roberto. O consumo, a concorrência, o mercado e as distorções da substituição tributária (para frente). Grandes questões atuais do direito tributário. $11^{\circ}$ Vol. São Paulo: Dialética, 2007.

FREITAS, Juarez. A interpretação sistemática do direito. 5. ed. São Paulo: Malheiros, 2010. FREITAS, Leonardo Buissa. A interpretação econômica no direito tributário brasileiro. Revista Bimestral de Direito Público. n. 52. p. 185-203. São Paulo, 2008.

GRAU, Eros Roberto. A ordem econômica na Constituição de 1988. 9ª Ed. São Paulo: Malheiros, 2004, Capítulo 3.

GRAU, Eros Roberto. Por que tenho medo dos juízes (a interpretação/aplicação do direito e os princípios). $6^{\mathrm{a}}$ Edição refundida do "ensaio e discurso sobre a interpretação/aplicação do direito. São Paulo: Malheiros, 2013. 
GUASTINI, Riccardo. Das fontes às normas. Tradução: Edson Bini. São Paulo: Quartier Latin, 2006.

HANS, Kelsen. Teoria Pura do Direito. Tradução: João Baptista Machado. 6. ed. São Paulo: Martins Fontes, 1998.

MACHADO, Hugo de Brito. Curso de Direito Constitucional Tributário. 2. ed. São Paulo: Malheiros Editora LTDA, 2015.

MACHADO, Hugo de Brito. Ordem econômica e tributação. In. FERRAZ, Roberto (coord.). Princípios e limites da tributação 2: os princípios da ordem econômica e a tributação. São Paulo: Quartier Latin, 2009.

MAXIMILIANO, Carlos. Hermenêutica e aplicação do direito. 19. ed. Rio de Janeiro: Forense, 2005. .

NOGUEIRA, Ruy Barbosa. Da Interpretação e da Aplicação das Leis Tributárias. 2. ed. São Paulo: Revista dos Tribunais, 1965.

PISCITELLI, Tathiane dos Santos. Os Limites à Interpretação das Normas Tributárias. São Paulo: Quartier Latin, 2007.

REIS, Luciana Silva. Direito e método: a contribuição de Ronald Dworkin. 2013. Dissertação (Mestrado em Filosofia e Teoria Geral do Direito) - Faculdade de Direito, Universidade de São Paulo, São Paulo, 2013. Disponível em: < http://www.teses.usp.br/teses/disponiveis/2/2139/tde-10012014-161528/pt-br.php>. Acesso em 09 out. 2019.

SILVA, José Afonso da. Curso de Direito Constitucional Positivo. 38 ed. São Paulo, Malheiros, 2015.

STRECK, Lênio. Hermenêutica jurídica e(m) crise: uma exploração hermenêutica da construção do direito. 10. ed. Porto Alegre: Livraria do Advogado, 2011.

TESAURO, Francesco. Instituições de Direito Tributário. Tradução: Fernando Aurelio Zilveti e Laura Fiori Ferreira. São Paulo: IBDT, 2017. 
VANONI, Ezio. Natureza e interpretação das leis tributárias. Rubens Gomes de Sousa (trad.). Rio de Janeiro: Edições Financeiras, s.d. (título original: Natura ed interpretazione delle leggi tributarie. Padova: CEDAM, 1932).

VILANOVA, Lourival. As Estruturas Lógicas e o Sistema de Direito Positivo. $4^{\mathrm{a}}$ ed. São Paulo: Noeses, 2010.

WARAT, Luis Alberto. O direito e sua linguagem. 2. ed. Porto Alegre: Sérgio Fabris, 1995.

SPONCHIADO NETO, Silvio. Técnicas decisórias de ponderação: por uma busca de limitação ao subjetivismo judicial. 2016. Dissertação (Mestrado em Desenvolvimento no Estado Democrático de Direito) - Faculdade de Direito de Ribeirão Preto, Universidade de São Paulo, Ribeirão Preto, 2016. Acesso aos 09 out. 2019. 